\title{
Biochemical and Morphological Modifications in a Patient with Acromegaly in Correlation with Oral Rehabilitation
}

\author{
MARIANA CONSTANTINIUC ${ }^{1}$, VERONICA MERCUT ${ }^{2}$, MONICA SCRIECIU ${ }^{2}$, ANA ISPAS ${ }^{1}$, DANIELA POPA ${ }^{1 *}$, IOANA DUNCEA ${ }^{1}$ \\ IIuliu Hatieganu University of Medicine and Pharmacy, Department of Prosthetic Dentistry, 8 Victor Babes Str., 400000, \\ Cluj-Napoca, Romania \\ Unniversity of Medicine and Pharmacy, Faculty of Dental Medicine, Department 1, Discipline of Prosthetic Dentistry, 2 Petru \\ Rares Str., 200349, Craiova, Romania
}

\begin{abstract}
The purpose of this study was to evaluate the persistence of prosthetic treatment in a patient with morphological and biochemical alterations specific to acromegaly, which consists of a fixed prosthetic restoration. Acromegaly is a chronic multi-systemic endocrine disease due to an excess of hormones ( $\mathrm{GH}=$ growth hormone) or growth factor (IGF-1 insulin-like growth factor) attributed to pituitary disorders. Morphological signs and symptoms of acromegaly are particularly visible in the face and extremities. We performed a prosthetic therapy to a 36-year-old acromegaly patient, consisting of a full arch bridge for maxilla and three mandible bridges. We applied an original method for reducing the thickness of the metal on the occlusal surface of the crowns. We have observed the evolution of the patientfor 20 years. Morphological changes over time in the mandible arch have caused the decementation of the bridge in the frontal area and the enhancement of the lateral cross-bite, insignificant changes that did not endanger dento-maxillary functionality. The case treated by us demonstrates that fixed dentures can be applied to acromegaly patients with multiple edentations, with the condition of supervising the patient over the time.
\end{abstract}

Keywords: acromegaly, prosthetic rehabilitation, bridge, occlusion

Acromegaly is a rare disease caused by a persistent hypersecretion of growth hormone (GH), almost always due to a pituitary adenoma [1]. The term acromegaly is derived from the Greek words Akron (extremities) and Megas (great) [2]. Pierre Marie, a renowned French neurologist, published the first description of the disease and its pathology [3]. The annual incidence of the disease is $3-5$ cases per one million inhabitants, and the prevalence is 30-60 cases per one million inhabitants [4,5].

The hypersecretion of $\mathrm{GH}$ may increase serum levels of insulin-like growth factor 1 (IGF-1), which may affect energy homeostasis, and cause complications in metabolic, cardiovascular, or skeletal systems $[6,7]$. Comorbidities are prevalent and mortality is high, especially if biochemical control is not achieved [8,9]. Acromegaly often evolves insidiously, for a long time, taking even 8-10 years from onset to diagnosis [10]. The definitions of biochemically controlled disease and cure have changed over the years regarding treated acromegaly. In 2010, biochemical remission was defined as a normal ageadjusted IGF-I along with suppressed $\mathrm{GH}<0.4 \mu \mathrm{g} / \mathrm{L}$. In 2014 the level for suppressed GH was raised to $<1.0 \mu \mathrm{g} / \mathrm{L}$ $[11,12]$. The primary objective of therapy is to lower the growth hormone level to a diurnal average concentration $<2.5 \mu \mathrm{g} / \mathrm{L}$ or randomized GH $<1 \mu \mathrm{g} / \mathrm{L}$ with IGF- $1 \leq \mathrm{LSN}$ (the upper limit of the normal value interval [13]. The clinical manifestations are caused by increased $\mathrm{GH}$ and insulin-like growth factor-1 (IGF-1) levels, as well as the compression of structures adjacent to the pituitary tumor and the possible concomitant diminished secretion of other pituitary hormones [14]. Skin thickens due to glycosaminoglycan deposits and increased collagen production by the connective tissue. Deformation of the bones specifically affects the column, showing superior dorsal chest and compensatory lumbar hyperlordosis. Simultaneously, hypertrophy of laryngeal tissues occurs in the vocal cords, resulting in a deep voice and slow speech [15-17]. The facial morphology is altered by thickening the features [18]. The most relevant oral symptoms are the mandibular prognatism, macroglossia and lower teeth spacing [19]. Cephalometric measurement and Combine Computer Tomography reveal bone changes in the mandible $[20,21]$

The therapeutic objectives are to remove the tumor or at least control its volume, avoiding compression symptoms; to normalize the GH and IGF-1 levels; to control the symptoms and comorbidities; and to prevent premature mortality [22]. Disease activity may persisteven after surgical removal of the adenoma, thus reflecting the complexity of treatment and the need for a multimodal multidisciplinary approach [23].

In this context, oral rehabilitation treatment becomes very difficult due to the fact that the growth of the jaw bone can continue even under the conditions of tumor ablation. The gold standard in oral rehabilitation is fixed prosthesis, which offers manyadvantages over removable denture, but in the context of this condition, it has an unfavorable prognosis.

The purpose of this study was to present the prosthetic treatment performed in a patient with acromegaly and to evaluate their perenniality after a considerable number of years. Considering the general condition of the patient, the therapeutic decision had a certain risk associated with the possibility of further bone growth, especially at the level of the cephalic extremity.

\section{Experimental part \\ Material and methods}

We present the case of a 56-year-old acromegaly patient who, 20 years ago, addressed to the Restorative Department of the Cluj-Napoca Dental School for prosthodontic treatment, signaling serious functional disorders of the dento-maxillary apparatus. The protocol was approved by the Ethical Committee of University of Cluj-Napoca, Romania (No. 130/06.05.2019) and the patient had signed the informed consent The patient was

*email: popa.daniela@umfcluj.ro,Phone: 0744349278 
in the Clinic of Endocrinology Cluj-Napoca with the diagnosis of acromegaly secondary to a pituitary adenoma with post-operatory relapse. The facial objective examination in the frontal and lateral norm has revealed aspects which are characteristic of the disease (fig. 1).
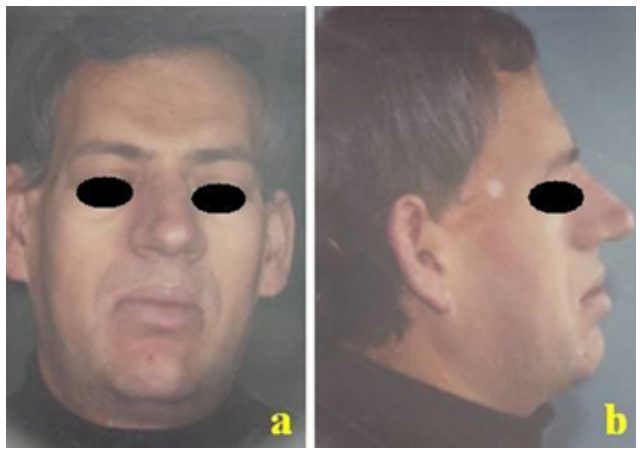

Fig. 1. Initial facial appearance, characteristic for acromegaly, of the frontal (a) and lateral (b)

The lateral cephalometryc analysis showed obvious changes consisting in enlargement of the mandible, of the Sella turcica and the paranasal sinuses (fig. 2).
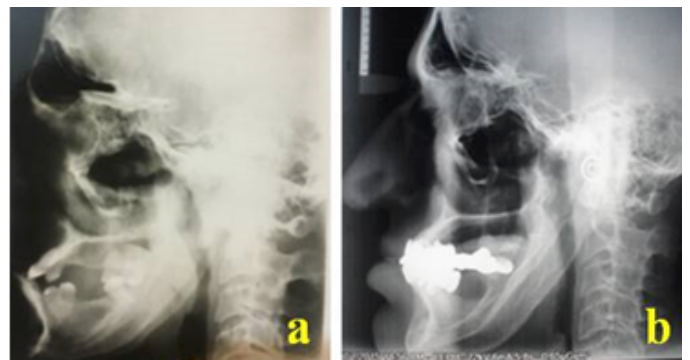

Fig. 2. The patient's lateral cephalometry performed at the first and last examinations reveal the enlargement of the paranasal sinuses, the gonial angle enlargement, the mandibular prognatism, the class III profile.

The endobuccal examination revealed the following pathological changes: maxillary and mandibular partial edentation, lack of occlusion contacts, cross bite, pronounced spacing and the lower front teeth buccally inclined, negative overjet, consequently, the impossibility of chewing and pain at mouth closure.

Considering that the patient's condition was stationary, fixed partial denture (FPD) solution was adopted, taking into account the removal of fixed dentures in case of a new growth relapse.

In the clinical and technical stages of the prosthetic treatment, we mention only a few particular aspects. Due to the extremely large mandible, the stock rim-lock tray had to be modified. The determination of the inter-maxillary relationship was accomplished with physiological methods and occlusal rims, establishing a therapeutic occlusion, which we tested for 3 months with the help of temporary acrylic bridge. During the final treatment we have made FPD with a chromium-cobaltalloy metal frame and a composite physiognomic component. In the frontal area, edge-to-edge occlusion was performed and cross bite in the lateral areas (fig. 3).

As a technique for crowns realization, a particular process, imposed by the necessity of increasing the height of the artificial crowns, was used. In the wax model, another frame, distinct from the crown frame itself, was located between the framework and the occlusal surface of the FPD (fig. 4).

This has made it possible to obtain an adequate thickness of the occlusal surface, facilitating the cutting in the event of an ablation of the prosthetic restoration, imposed by the worsening of the disease. After completing

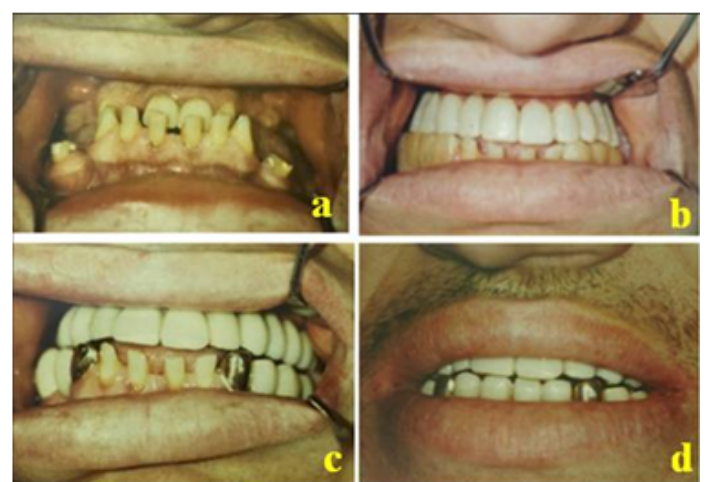

Fig. 3. Stages of prosthetic treatment: initial intraoral aspect (a), temporary dentures (b), final prosthetic restorations in lateral areas (c), frontal area occlusion reports (d).
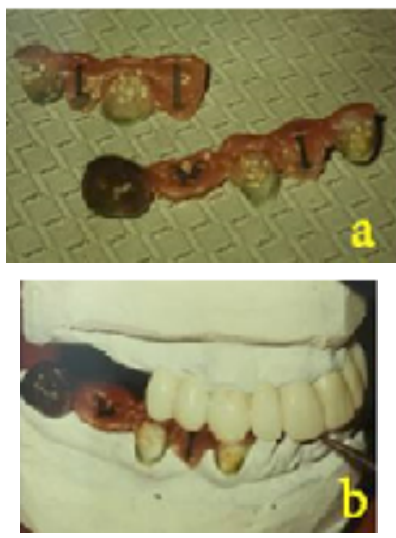

Fig. 4. FPD wax patterns, with overlapped boxes between the capes and occlusal platform

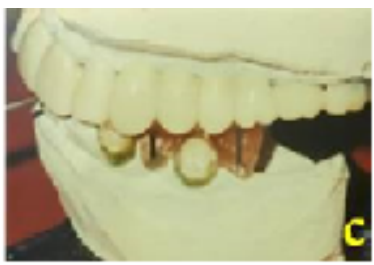

the prosthetic restorations, the patient was instructed not to perform the incision of food and recommended regular checks.

\section{Results and discussions}

The prosthetic treatment was functional for 20 years, with some minor modifications that could be remedied by keeping the lateral prosthetic restorations. The FPD was decemented from the frontal mandibular teeth due to the disease relapse. In addition, the endobuccal objective exam revealed: increased cross-bite occlusion in lateral areas, maintaining good stability of the FPD and a good fixation of the upper teeth in the maxillary, loss of marginal fit of the crowns to teeth 1.4 and 2.3. The patient does not claim functionality deficiencies. [41]

We recommended the replacement of prosthetic restorations. Taking into account the possible enlargement of the mandible arch, due to the unfavorable evolution of the disease, it was necessary to make two front FPD with the preservation of the diastema (fig. 5).
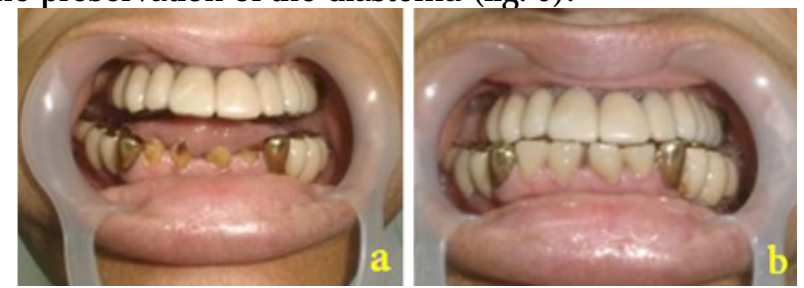

Fig. 5. Endobuccal changes occurring within 20 years, followed by decementation of mandibular FPD (a), and mandibular FPD restored in occlusal edge-to-edge position 
Despite the increase in facial changes caused by relapse of the disease, the patient has preserved the functionality and aesthetics of prosthetic restorations made 20 years ago.

Acromegaly is a rare disease with a prevalence of about 60 cases/million, with no geographical differences [2, 3, 24], the frequency in men aged 20-40 years [25]. In our patient, the disease occurred at the age of 32 years. The main feature is the hypertrophy of adjacent bone and soft structures, most often affecting the bones of the face, skull, fingers and legs [25]. Weakening of bone quality may determine some problems of the temporomandibular joint, bone resorption and therefore it may lead to teeth loss [26].

In literature, in the few publications on the treatment of patients with acromegaly, removable partial dentures are described.

As in young and children patients, in patients with acromegaly, the application of fixed partial prostheses poses a risk of further developing bones, especially of the jaw bone. Considering that the patient was in a stationary state, the solution of fixed prosthesis was adopted. The patient was advised to attend periodic controls at 6 months atthe Endocrinology Clinic and Dental Clinic. This treatment plan has been adopted, with the physician's availability to perform removable dentures in case of a new mandibular growth. [42]

In the clinical and technical steps of prosthetic treatment, we mention only a few particular aspects. At the preliminary impression, the first problem was because of the extremely large mandible, exceeding the stock rimlock tray that was modified with a modeling composition. Determination of intermaxillary relationships were made as in total edentation, using occlusion rims and different methods for determining the vertical dimension of occlusion: rest position, swallowing and phonation. We set the vertical size of occlusion so as to keep the interocclusal distance of $4 \mathrm{~mm}$ during speech and $6 \mathrm{~mm}$ in the physiological rest of the mandible.

We have established a therapeutic occlusion, which we tested for 3 months with temporary acrylic restorations. By the therapeutic occlusion, we sought to obtain the mandibular-maxillary relationship that would ensure the comfort and freedom of functioning of the temporomandibular joint and, on the other hand, would favor convenient occlusal contacts. [40]

In the frontal area, we opted for edge-to-edge occlusion and in the right lateral area for a cross-bite with a slight circumscription of upper buccal cusps by lower buccal cusps. This type of occlusion resulted from the intermaxillary relationships that we have established, these not being a brake on the possible increase in the mandible caused by the disease. The four lower incisors were lingually inclined to achieve the edge-to-edge relationship with the upper incisors.

As a technique for mixed crowns, a particular process, different from the classic one, was used. The original method was imposed by the increased vertical dimension of occlusion and the therapeutic position of the mandible. Due to the increased dimensions of the vertical branch of the mandible and the posterior position of the mandibular condyles in the glenoid cavity, a significant distance was created between the prosthetic occlusion plane and the occlusal surface of the remaining teeth. Consequently it was necessary to increase the height of the artificial crowns. Because the metallic occlusal surface does not become too thick, the wax layouthas another carve distinct from the box for acrylic veneer of the crown, resulting in a double box with a vestibular and an occlusal component.
Due to this method we have avoided the disadvantage of the excessive weight of the prosthetic restoration and the excessive thickness of the crown's occlusal surface, which would make it extremely difficult to cut when remove them. The fact of having a normal thickness of the occlusal frame is essential in the case of the need of ablation of the prosthetic restoration, in the event of a new jaw growth [43].

The existence of a sufficient number of the remaining teeth, with a good odonto-periodontal and implant condition, in the initial phase of treatment, determined the fixed partial dentures decision.

Undoubtedly, the comfort provided by the fixed restorations is superior to that offered by the removable dentures, the more so as the patient had a sufficient number of outstanding teeth. Additionally, in the case of removable restorations, their retention and stability would be severely compromised by the inverse occlusion, due to the disproportionate development of the two jaws.

By augmenting the vertical dimension of occlusion through temporary partial denture, we have achieved a reduction in the trend towards class 3 malocclusion, which has allowed us to achieve an edge-to-edge incisal relationship, the proposed therapeutic solution by other authors [27-29]. In this way an inter-occlusal space was created, sufficient to achieve the prosthetic restoration of the anterior teeth after this occlusal pattern and the posterior teeth in cross-bite occlusion [27], allowing the masticatory forces to be transmitted to the maxillarybones at a favorable angle [30].

The dentist can have a significant contribution to the diagnosis of acromegaly due to specific endo-buccal signs, especially related to obvious changes in occlusal relationship due to mandible growth and tooth spacing [31, 32 , 43]. Another possible method for early diagnosis of patients with acromegaly is to use software in order to detect the features of acromegaly, using photographs of the face. This could be a promising system for identifying the disease [33, 34].

The increase in the total length of the mandible may be asymmetric [35]. In our patient there was initially asymmetry only in the right hemiarch, then left, following the slow growth process. Also, the decementation of the FPD on the lower front teeth could be caused, at least in part, by the same mandible growth process. Some manifestations respond well to decreased GH level; although some changes are irreversible [36].

Prosthetic rehabilitation of any patient is also aesthetic, not justrehabilitation of dento-maxillary function [37]. Even in acromegaly patients, their preferences are directed towards a functional and aesthetic prosthetic treatment [30] which also applies to our patient.

We have chosen the FPD solution for the aforementioned reasons, in the spirit of the prosthetic and ethical principles that the dentists have to follow [27, 38, 39], distinguishing from the cases presented in the literature, in which were made removable partial dentures.

\section{Conclusions}

Facial and odonto-maxillary changes are common in acromegaly, with aesthetic and functional consequences on the quality of life of the patient, requiring the correct recovery of these functions. Fixed partial dentures applied to this acromegaly patient have yielded satisfactory results on several levels: functionality, aesthetics, stability of mandibular-maxillary relationships for a long time. Fixed partial dentures are preferred by patients because they are more easily assimilated psychologically and biologically 
integrated into the functioning of the dento-maxillary apparatus. Their recommendation to the acromegaly patient involves certain limits, depending on the severity of the morphological changes and the evolutionary stage of the disease.

Prosthetic treatment of the patient with acromegaly is achieved through close cooperation between doctors of various specialties, primarily endocrinologists and dentists. The time tracking of these patients is mandatory in order to intervene when major changes occur in the evolution of the disease, requiring the replacement of existing dentures.

\section{References}

1.MELMED, S., J. Clin. Invest., 119, 2009, p. 3189

2.CHANSON, P., SALENAVE, S., J. Rare Dis., 3, 2008, p. 1

3.MILANJ EET KAUR, M., SHAILAJA, S., CHANDRA, S, MAMATHA, B., J. Adv. Oral Res., 3, nr.2, p.17

4.DINEEN, R., STEWART, P.M., SHERLOCK, M., QJ M, 110, 2017, p. 411

5.SESMILO, G., Endocrinol Nutr., 60, 2013, p. 470

6.MELMED, S., N. Engl. J. Med., 355, no. 2558, 2006, p. 73

7.COLAO, A., FERONE, D., MARZULLO, P., LOMBARDI, G., Endocr.Rev., 25, no. 102,2004 , p. 52

8.LESEN, E., GRANFELDT, D., HOUCHARD, A., DINET, J., BERTHON, A., OLSSON, D.S., et al., Eur. J. Endocrinol., 176 , 2017, p. 203 9.FUCHTBAUER, L., OLSSON, D.S., BENGTSSON, B.A., NORRMAN, L.L., SUNNERHAGEN, K.S., JOHANNSSON, G., Eur. J. Endocrinol., 177, 2017, p. 217

10.MELMED, S., N. Engl. J. Med., 322, no.14, 1990, p. 966

11.GIUSTINA, A., CHANSON, P., BRONSTEIN, M.D., KLIBANSKI, A., LAMBERTS, S., CASANUEVA, F.F., et al., J. Clin. Endocrinol. Metab., 95,2010, p. 3141

12.KATZNELSON, L., LAWS JR., E.R., MELMED, S., MOLITCH, M.E., MURAD, M.H., UTZ, A., et al., J. Clin. Endocrinol. Metab., 99, 2014, p. 3933

13.KASHYAP, R., BABU, G., SHETTY, S., J. Oral. Sci., 53, 2011, p. 133 14.CORDIDO, F., GARCIA ARNES, J.A., MARAZUELA ASPIROZ, M., TORRES VELA, E., Endocrinol Nutr., 60, no. 457, 2013, p. 1

15.KASHYAP, R., BABU, G., SHETTY, S., J. Oral. Sci., 53, 2011, p. 133

16.McKENNA, G., HAYES, M., BURKE, F.M., P Eur. J. Prosthodont. Rest. Dent., 22, no. 3, 2014, p. 98

17.MIRANDA-RIUS, J., BRUNET-LLOBET, L., LAHOR-SOLER, E., DE DIOS-MIRANDA, D., GIMÉNEZ-RUBIO, J.A., Head \& Face Medicine, 13, 2017, p. 1

18.CORDERO, R.A., BARKAN, A.L., Rev Endocr Metab Disord., 9, 2008, p. 13

19.MIRANDA-RIUS, J., BRUNET-LLOBET, L., LAHOR-SOLER, E., DE DIOS-MIRANDA, D., GIMENEZ-RUBIO, J.A., Head \& Face Medicine, 13, 2017, p. 1

2OHERRMANN, B.L., MORTSCH, F., BERG, C., WEISCHER, T., MOHR, C., MANN, K., Exp. Clin. Endocrinol. Diabetes, 119, no. 1, 2011, p. 9 21.KARAKIS, D., AKTAS-YILMAZ, B., DOGAN, A.,YETKIN, I., BEK, B.,
Med. Oral. Patol. Oral Cirugia Bucal, 19, 2014, p. 1 22.BERNABEUA, I., CAMARAB, R., MARAZUELAC, M., PUIG DOMINGOD, M., Endocrinol Diabetes Nutr., 65, no. 8, 2018, p. 428 23.GIUSTINA, A., CHANSON, P., KLEINBERG, D., BRONSTEIN, M.D., CLEMMONS, D.R., KLIBANSKI, A., et al., Nat. Rev. Endocrinol., 10, 2014, p. 243

24.HOLDAWAY, I.M., RAJ ASOORYA, C., Pituitary, 2, 1999, p. 29

25.SACHERMAN, R.H., J. Pros. Den., 5, no. 2, 1955, p. 186

26.BURLUI, A., SACHELARIE, L., ROMILA, L.E., FARCAS, D.M., IJMD, 23, no.1, 2019, p. 134

27.MCKENNA, G., HAYES, M., BURKE, F.M., Eur. J. Prosthodont. Rest. Dent., 22, no.3, 2014, p. 98

28.WHITE, S.C., PHAROH, M.J., Oral Radiology: Principles and Interpretation. 6th Edition, Elsevier, St Louis, USA. p. 458

29.SCACCHI, M., CAVAGNINI, F., Pituitary, 9, no. 4, 2006, p. 297

30.KARAALIOĐLU, Y.D., Atatürk Üniv. Dis Hek. Fak. Derg., 19, no. 1, 2009, p. 41

31.LUGO, G., PENA, L., CORDIDO, F., Int. J. of Endocrinol., 2012, p.1 32.DRANGE, M.R., FRAM, N.R., HERMAN-BONERT, V., MELMED, S., J. of Clin. Endocrinol. And Metabol., 1, 2000, p. 168

33.SCHNEIDER, H.J ., KOSILEK, R.P., GUNTHER, M., et al., J. of Clin. Endocrinol. and Metabol., 96, no. 7, 2011, p. 2074

34.KONG, X., GONG, S., SU, L., HOWARD, N., \& KONG, Y. EBioMedicine, 27, 2018, p. 94

35.KUNZLER, .A, FARMAND, M., J. Cranio-Maxillo-Fac. Surg., 19, 1991, p. 332

36.BEN-SHLOMO, A., MELMED, S., Clin in Dermat, 4, 2006, p. 256

37.ASHOK, V., NALLASWAMY, D., BEGUM, S.B., NESAPPAN, T., J. Indian Prosthodont. Soc., 14, no.1, 2014, p. 279

38.LYNCH, C.D., ALLEN, P.F., Br. Dent. J., 198, 2005, p. 17

39.LYNCH, C.D., ALLEN, P.F., Br. Dent. J., 200, 2006, p. 277

40.EARAR, K., GRIGOROIU, R., SCUTARIU, M.M., Effect of the Sandblasting process on the Surface Properties of Dental Zirconia, Rev.Chim.(Bucharest), 68, no. 7,2017, p.1560-1564, July 2017

41.EARAR, K., ANTONIAC, V. I., BACIU, S., Etching Treatment Effect on Surface Morphology of Dental Structures, Rev.Chim.(Bucharest), 68, no. 11,2017, p.2700-2703

42.FORNA, N., CIMPOESU, N., SCUTARIU, M.M., Study of the ElectroCorrosion Resistance of Titanium Alloys Used in Implantology, Conference: $3^{\text {rd }}$ International Conference on E-Health and Bioingineering (EHB), Location: Univ. Med. \& Pharm., Iasi, Romania, Nov. 24-26, 2011

43.CERGHIZAN, D., EARAR, K., SCUTARIU, M.M., In Vitro Study on the Dimensional Stability of Interocclusal Recording Materials, Mat.Plast., 54, no. 3,2018, p.557-564

$\overline{\text { Manuscript received:11.01.2019 }}$ 